\title{
Why the social sciences are irreducible
}

\author{
Tobias Hansson Wahlberg ${ }^{1}$
}

Received: 26 June 2016 / Accepted: 15 June 2017 / Published online: 29 June 2017

(C) The Author(s) 2017. This article is an open access publication

\begin{abstract}
It is often claimed that the social sciences cannot be reduced to a lowerlevel individualistic science. The standard argument for this position (usually labelled explanatory holism) is the Fodorian multiple realizability argument. Its defenders endorse token-token(s) identities between "higher-level" social objects and pluralities/sums of "lower-level" individuals (a position traditionally called ontological individualism), but they maintain that the properties expressed by social science predicates are often multiply realizable, entailing that type-type identities between social and individualistic properties are ruled out. In this paper I argue that the multiple realizability argument for explanatory holism is unsound. The social sciences are indeed irreducible, but the principled reason for this is that the required token-token(s) identifications cannot in general be carried through. In consequence, paradigmatic social science predicates cannot be taken to apply to the objects quantified over in the lowerlevel sciences. The result is that typical social science predicates cannot even be held to be co-extensive with individualistic predicates, which means type-type identifications are ruled out too. Multiple realizability has nothing to do with this failure of co-extensiveness, because the relevant social science predicates are not multiply realized in the sense intended by the explanatory holists, a sense which presupposes reductive token-token(s) identifications.
\end{abstract}

Keywords Explanatory holism $\cdot$ Explanatory individualism $\cdot$ Reduction $\cdot$ Composition as identity $\cdot$ Ontological individualism $\cdot$ Multiple realization

Tobias Hansson Wahlberg

tobias.hansson_wahlberg@fil.lu.se

http://www.fil.lu.se/en/person/TobiasHanssonWahlberg

1 Department of Philosophy, Lund University, LUX, Helgonavägen 3, Box 192 (Billing address Box 188), 22100 Lund, Sweden 


\section{Introduction}

Philosophers and social scientists have long debated whether social sciences such as sociology, anthropology, political science and economics are reducible to some individualistic theory referring only to individuals and their interactions. ${ }^{1}$ Explanatory holists think they are not, explanatory individualists that they are (at least in principle). Explanatory individualism used to be popular (see e.g. Watkins 1957/1994, and Oppenheim and Putnam 1958, for influential defenses), but nowadays the orthodoxy appears to be that explanatory holism is the correct view. Following Jerry Fodor (1974/1994), modern explanatory holists have generally defended their position on the grounds that characteristic social science predicates can usually be correlated only with a "wild disjunction" of individualistic predicates (e.g. Sawyer 2002, pp. 549-550). In the material mode, their point is that social properties (understood as types) tend to be multiply realizable (e.g. Kincaid 1986/1994; Little 1991; Sawyer 2002, 2005, Ch. 5). Typically, however, these same explanatory holists hold that particular social objects - that is, objects consisting of many individuals (such as teams, organizations and bureaucracies) — can be identified with pluralities or sums of (suitably interrelated) individuals, a position traditionally labelled ontological individualism (I will return to this terminological matter in Sect. 3). Indeed, in its standard form, the argument from multiple realizability presupposes that token-token(s) identities of the relevant sort obtain. (Henceforth I will simply write "token-token" identities; this simpler expression should be understood to cover both one-many and one-one identities. If the reductive relata are pluralities of individuals, then we are concerned with one-many identifications; if they are sums orsets of individuals, then arguably we are concerned with one-one identifications-see Sects. 4 and 5 for the details.)

In this paper I shall endeavor to show that the influential Fodorian multiple realizability argument for explanatory holism is mistaken. I will argue, following the lead of a number of philosophers (e.g. Ruben 1985, Ch. 1; Schmitt 2003, Ch. 1; Uzquiano 2004; Ritchie 2013), that reductive token-token identities cannot be defended for social objects - at least, as they are characterized in current social science. I will point out that this failure is the principled reason why explanatory holism is correct. (The

\footnotetext{
${ }_{1}$ Arguably, the lower-level individualistic theory should be allowed to talk about individuals' artifacts and their material environment in general (cf. Epstein 2009; but see already Watkins 1957/1994 and Bhargava 1992, pp. 159-161). However, for the most part I will ignore this liberalized stance on individualism. The key points of this paper, which concern problematic aspects of the required token-token(s) identifications, will be largely unaffected if the constraints on individualistic theories are loosened up in the way indicated (see Sect. 5). For the purposes of this paper, the crucial restrictions on individualistic theories are merely that they should not, in referentially transparent contexts, explicitly refer to manifestly social objects (i.e. wholes consisting of many individuals) or to social properties (i.e. properties characteristically held by social objects, such as being a team, being an organization and being a church) (cf. Tuomela 1995, p. 367). Mereological sums and sets of individuals are often taken to be "admissible" individualistic objects (see e.g. Schmitt 2003, p. 2), but I think it is questionable that they are-I will return to this issue in Sect. 4. Note also that in this paper I am using the terms "explanatory holism" and "explanatory individualism" in restricted senses, as being exclusively about inter-theoretic reduction. Sometimes these terms (and their equivalents "methodological holism" and "methodological individualism") are used in more relaxed senses that are not directly tied to the question of inter-theoretic reduction but to explanatory issues more loosely conceived (for useful overviews, see e.g. Bhargava 1992, Ch. 1; Zahle and Collin 2014, Ch. 1; Zahle 2016; see also Ruben 1985, Ch. 3).
} 
literature just mentioned contains little discussion of how rejection of token-token identities bears on the issue of inter-theoretic reduction.) Finally, I will argue that when the thesis of reductive token-token identities is given up, the multiple realizability argument, as it is deployed by the Fodorian explanatory holists, can no longer be successfully made.

The structure of the paper is as follows: I begin by discussing conditions for theory reduction (Sect. 2). Along with most theorists engaged in the explanatory individualism/holism debate, I adopt a strengthened version of classical Nagel-reduction requiring the connectability of the relevant theories via bridge principles expressing both type-type and token-token identities. Section 3 describes the Fodorian multiple realizability argument for explanatory holism. In Sect. 4, I present arguments for the claim that token-token identities between social and individualistic objects cannot be coherently advocated. In Sect. 5, I discuss possible ways of circumventing these arguments - escape routes that involve adopting a four-dimensional framework. I argue, however, that the four-dimensional move is ultimately unsuccessful. In Sect. 6, I briefly present what I take to be the defensible form of the bridge principles, but since the principles fall short of expressing token-token identities, I conclude that reduction fails. I subsequently go on to show, in Sect. 7, how the Fodorian multiple realizability argument for explanatory holism collapses once reductive token-token identities are given up. In Sect. 8, I draw together some concluding remarks.

\section{Conditions for theory reduction}

There are many theories of theory reduction, but philosophers and social scientists engaged in the explanatory individualism/holism debate have generally operated with a strengthened version of classical Nagel-reduction, and I will follow suit. ${ }^{2}$ Roughly, according to the Nagel paradigm (Nagel 1961/1979, Chs. 5 and 11), a scientific theory $T_{s}$ (a secondary science) reduces to a theory $T_{p}$ (a primary science) iff the laws of $T_{s}$ are deducible from some laws of $T_{p}$ together with bridge principles connecting the expressions of $T_{S}$ with expressions in $T_{p} \cdot{ }^{3}$ Nagel himself was neutral on the exact form

\footnotetext{
2 The classic Nagel-model of theory reduction has been criticized in various ways over the years (as noted e.g. by Zahle 2016, Sect. 2.3), and I describe some key criticisms in the text below. The general approach, however, is alive and kicking: see e.g. Dizadji-Bahmani et al. (2010) for a general and powerful defense (although I would reject some of their claims - e.g., that bridge principles need not involve identities-as the critical discussion in the text below discloses).

3 Strictly speaking, bridge principles are needed only in the case of heterogeneous reductions, i.e. when the secondary science contains expressions not included in the primary science. The explanatory individualism/holism debate is often taken to concern the possibility of heterogeneous reduction because it is assumed that individualistic sciences do not contain predicates such as "is an organization" and "is a corporation". It should be noted, however, that nowadays individualistic sciences are often allowed to contain predicates such as "teacher", "inmate" and "president" (see e.g. Zahle 2003, pp. 85-87; Greve 2012, pp. 211-212), although historically it has often been argued that such predicates can be meaningfully deployed only within theories which also contain explicitly social predicates such as "school" and "prison" (e.g. Lukes 1968/1994). In this paper, I will ignore this latter issue. I will grant the individualists usage of such ostensibly "single person" predicates. Here my concern is with the (putative) satisfiers of ostensibly social social science predicates, i.e. social science predicates which are (supposedly) true of objects consisting of many individuals. It is predicates of this kind that are primarily discussed by Fodorian explanatory holists in the context of the
} 
of the bridge principles (he called them "rules of correspondence"). He allowed that they could be mere biconditionals of the form " $x$ is $S$ if and only if $y$ is $P$ ", where " $S$ " is a predicate of the secondary science and " $P$ " is a predicate of the primary science, and where the values of the $x$ and $y$ variables may be distinct objects (ibid: 101 and 355, $\mathrm{n}$. 5). However, later writers have considered such biconditionals too weak, insisting that in cases of genuine theory reduction bridge principles need to involve strict identities, not mere correlations, between the phenomena described by $T_{s}$ and $T_{p}$ (e.g. Schaffner 1967; Sklar 1967; Causey 1972; Fodor 1974/1994; Bhargava 1992). That is to say, the bridge principles should express both "token-token" and "type-type" identities.

There are several reasons for requiring theory reduction to involve token-token and type-type identities. First of all, one important goal of theory reduction is ontological parsimony (Smart 1959; Fodor 1974/1994, p. 688; Searle 1992, pp. 113-114; Clapp 2001; cf. Dizadji-Bahmani et al. 2010, p. 405), but reductions carried out with bridge principles of the sort mentioned by Nagel do not achieve this: they are compatible with full-blown dualistic, albeit perfectly correlated, ontologies. ${ }^{4}$ Moreover, "weak" or "liberal" Nagel-reductions do not explain why the relevant phenomena are perfectly correlated; they merely involve statements (bridge principles) to the effect that they are so correlated (Kim 2005, p. 100). By contrast, theory reductions stating tokentoken and type-type identities do explain the correlations: the relevant phenomena are "correlated" because they are identical (Bhargava 1992, p. 26, 68; McLaughlin $1992 / 2008$, p. 45). Thus, according to the critics of "weak" Nagel-reduction, fully fledged, truly explanatory theory reduction should involve not only derivability but ontological reduction as well (pace Dizadji-Bahmani et al. 2010, p. 405), i.e. it should involve both token-token and type-type identities. Importantly, the notion of theory reduction explicitly or implicitly employed in the modern explanatory individualism/holism debate has tended to be-rightly, in my view-the strengthened version of classical Nagel-reduction, and this is indeed the concept of theory reduction I will adopt in this paper. Thus, on this understanding of theory reduction, explanatory individualism entails ontological individualism in the strong token-token identities sense (see e.g. Bhargava 1992, p. 26).

Before I go on to explain why I think the Fodorian multiple realizability argument for explanatory holism is mistaken I should mention that in another respect Nagelian theory reduction has been deemed by some observers too stringent. Thus it has been maintained (primarily by Schaffner 1967, but see also Dizadji-Bahmani et al. 2010)

\footnotetext{
Footnote 3 continued

multiple realizability argument. Moreover, Nagel presupposed that $T_{p}$ and $T_{s}$ consist of law statements, an assumption that can be questioned in the case of social and individualistic sciences (see e.g. the papers in Martin and McIntyre 1994, part II). I will not enter this specific debate either. It should be observed, though, that the Fodorian explanatory holists maintain that social laws are employed in the social sciences (e.g. Fodor 1974/1994, p. 697; Kincaid 1990/1994; Sawyer 2002, p. 547); I shall simply assume, for the sake of argument, that they are correct about this. Thus, I will grant the Fodorians the applicability of the Nagelian framework to the social sciences, but argue that theory reduction fails nevertheless-for reasons differing from those traditionally defended by the Fodorian explanatory holists.

4 For example, substance dualism (although perhaps not of a strictly Cartesian sort) would not be ruled out if psychology were "reduced" to neurophysiology in this weak sense (Kim 1999, p. 12). And if psychology were "reduced" to neurophysiology with the help of bridge principles stating merely that the relevant token objects are the same, property dualism would not be ruled out (cf. Fodor 1974/1994, p. 688).
} 
that in order for $T_{S}$ to be reduced to $T_{p}$ it need not be the case that $T_{S}$ itself is derivable from $T_{p}$; it suffices that a corrected theory $T_{s} *$, strongly analogous to $T_{s}$, is derivable from $T_{p}$.

However, this modification of Nagel's original theory faces two serious objections, so I will not adopt it (for extensive discussion of the objections, see Winther 2009; Schaffner 2012). First, as yet we have no agreed, clear-cut criteria specifying when exactly two theories are strongly analogous. Hence, on this construal, the notion of theory reduction becomes undesirably vague and might give rise to irresolvable discussions about whether or not a certain theory has or has not been satisfactorily reduced. Secondly, if $T_{s} *$ is a modified version of $T_{s}$, suitably corrected to be derivable from $T_{p}$, then the original theory $T_{s}$ is deemed incorrect in the light of $T_{p}$, and $T_{s}$ is consequently rejected for the pair $<T_{s} *, T_{p}>$. But this rejection arguably involves theory replacement (in effect, the original theory $T_{S}$ is eliminated) rather than theory absorption, and it was the latter that Nagel was addressing in his (1961/1979: see e.g. p. 366). On the revised replacement version of theory reduction, a theory $T_{s}$ might be "reducible" to a theory $T_{p}$ although $T_{s}$ and $T_{p}$ are incompatible. A loose notion of theory reduction of this sort invites confusion.

Again, I find these two considerations persuasive, so I will eschew the weakened Schaffner version of Nagel's theory here. Specifically, in this paper I will investigate whether the social sciences in their current guise-postulating, as they do, changeable, non-extensional social wholes with kind-specific persistence conditions-are themselves in principle derivable (with the help of strong bridge principles expressing token-token and type-type identities) from an individualistic theory. Thus, I will be attending to the "descriptive metaphysics" of social science (cf. Strawson 1959, p. 9). This means I will largely neglect questions about how the social sciences might develop in the future. I think it is pretty pointless to speculate on such developments, and on the question whether future theories will, in some unspecified sense, be "strongly analogous" to current theorizing. Moreover, although it is not always clear whether the Fodorian explanatory holists adopt the strict absorption or looser replacement conception of theory reduction (even if it is clear that they require the bridge principles to state identities), it is plain that the arguments they present utilize examples from the social sciences in their current guise (see below, Sect. 3). I think, therefore, that I am justified in restricting my discussion in the way indicated.

\section{The Fodorian multiple realizability argument for explanatory holism}

Following Fodor (1974/1994) — who was concerned with "special sciences" in general, social sciences included (although his focus tended to be on psychology)—modern explanatory holists usually claim that the problem with social theory reduction lies in the failure of bridge principles to capture type-type identities between social and individualistic properties (e.g. Kincaid 1986/1994; Little 1991, Ch. 9; Sawyer 2002, 2005, Ch. 5). Most modern explanatory holists hold, however, that bridge principles expressing token-token identities can be developed: the general view is that particular social objects and events can be unproblematically identified with individualistic objects and events (e.g. Fodor 1974/1994, p. 698; Little 1991, p. 188; Sawyer 2002, 
p. 542; Kincaid 2009, p. 731). The alleged problem with type-type identities is that social properties are often multiply realizable - a point analogous to that once made by Hilary Putnam about reductionist accounts of mental properties (see the papers collected in Putnam 1975, but see also Fodor 1974/1994, pp. 692-693). More specifically, the complaint is that the properties expressed by social science sortal predicates, such as "is a peer group", "is an organization", "is a bureaucracy", "is a church", "is a nation state", and "is an institution", can be realized in various ways by distinct individuals interrelated in different ways (e.g. Kincaid 1986/1994, p. 500; Little 1991, p. 188, 194; Sawyer 2002, p. 545, 550). Thus, they are in effect saying (but they rarely go into much detail at this stage of the argument) that there is no single type of structural property-no single set of type relations-with which the social properties in question can be identified, although in each token instance of an organization, state, etcetera, individuals suitably interrelated exemplify the relevant social property.

Put in the formal mode, the objection is that the relevant bridge principles will have to involve "wild disjunctions" of predicates suitable to individualists (Fodor 1974/1994, p. 691; Kincaid 1986/1994, p. 500; Sawyer 2002, pp. 542, 549-550). Thus, the emerging bridge principles will often be of the following form (e.g. Fodor 1974/1994, p. 694; Sawyer 2002, p. 550):

$$
S x \equiv P_{1} x \vee P_{2} x \vee \ldots \vee P_{n} x
$$

According to Fodor, such bridge principles should be read as saying that "every event which consists of $x$ 's satisfying $S$ [a secondary science predicate] is identical with some event which consists of $x$ 's satisfying some or other predicate belonging to the disjunction $P_{1} \vee P_{2} \vee \ldots \vee P n$ [primary science predicates]" (Fodor 1974/1994, p. 694). ${ }^{5}$ If the distinct primary science predicates (" $P_{1}$ ", " $P_{2}$ ", . ., " $P$ ") express distinct properties $\left(P_{1} \neq P_{2}, P_{1} \neq P_{3}, \ldots\right)$, and if distinct primary science predicates are satisfied on different occasions (when the relevant secondary science predicate " $S$ " is satisfied), a bridge principle of this form will not affirm a type-type identity, the Fodorian explanatory holists insist, because then the transitivity of identity would be violated: if $S=P_{1}$, and $S=P_{2}$, then $P_{1}=P_{2}$; but $P_{1} \neq P_{2}$. Moreover, they reject the notion that a bridge principle of this form could be construed as saying that every event which consists of $x$ 's satisfying " $S$ " is identical with some event which consists of $x$ 's satisfying the disjunctive predicate " $P_{1} \vee P_{2} \vee \ldots \vee P_{\mathrm{n}}$ ". They reject the latter reading because they deny that the relevant disjunctive predicate expresses a genuine property — or, as Fodor puts it, a "natural kind". ${ }^{6}$ Hence, the emerging bridge

\footnotetext{
5 Taken literally, however, this reading must be nonsense. The predicates " $S$ " and " $P_{1}$ "..." $P_{\mathrm{n}}$ " are all distinct; thus, an event which consists of $x$ 's satisfying predicate " $S$ " cannot be identical with one consisting of $x$ 's satisfying some of the distinct predicates " $P_{1}$ "..." $P_{\mathrm{n}}$ ": these events must be distinct, since they involve the satisfaction of distinct predicates from distinct sciences. The relevant event identity must involve the properties expressed by the predicates. However, since the properties expressed by " $S$ " and " $P_{1}$ ". . " $P_{\mathrm{n}}$ " are explicitly claimed to be distinct (at least as types) it is difficult to see how event identity can be maintained even on this reinterpretation-unless some kind of trope theory is tacitly assumed. I develop this remark further below, and in particular in Sect. 7.

6 On Fodor's construal natural kinds are properties picked out by the predicates in proper laws, but he argues that the relevant disjunctive predicates do not, and will not, figure in proper laws at the primary
} 
principles do not involve property identity at type level. According to the explanatory holists in question, this means that genuine theory reduction is ruled out, since theory reduction requires type-type identities. (Of course, their argument goes through only if it is assumed that " $S$ " expresses a genuine property or "natural kind"; cf. Kim 1992.7)

Now, as noted above, these explanatory holists, although they reject type-type identities between social and individualistic properties, nevertheless endorse tokentoken identities between social and individualistic objects and events. Specifically, and fundamentally, they are committed to the notion that token social objects are identical with token individualistic objects. This can be seen by the following three interrelated considerations:

First, the Fodorian explanatory holists hold that an event is an object instantiating a property at a time. This view of events is often called the property exemplification view of events. Sawyer states: "I take an event to be the instantiation of properties by an object at a time [...] this thesis presupposes an ontology in which it is objects that have properties" (2002, p. 541). Kincaid claims that "Social events and processes are then events and processes involving social entities", where social entities are "classes, castes, nations, churches, bureaucracies, peer groups etc.” (1986/1994, p. 498).

Now, as Kim has persuasively argued (1976/1993, p. 35), the identity condition for events, thus understood, is simply:

$[x, P, t]=\left[y, Q, t^{\prime}\right]$ iff $x=y, P=Q$, and $t=t^{\prime}($ where $[\ldots, \ldots, \ldots]$ is an event, $x(y)$ is an object, $P(Q)$ a property, and $t\left(t^{\prime}\right)$ a time $)^{8}$

Thus, if a token social event is identical with a token individualistic event, as these holists maintain, ${ }^{9}$ then the objects involved in these events must be identi-

Footnote 6 continued

level: statements containing such disjunctive predicates cannot support appropriate counterfactuals (Fodor 1974/1994, p. 691; see also Kincaid 1986/1994, p. 503). See Armstrong (1989, pp. 82-84) and Mellor (1995, pp. 196-199) for further arguments against disjunctive properties. For an attempt to make sense of disjunctive properties, see Clapp (2001). I should add in this context that the Fodorians allow that "natural kinds" may be social or cultural properties-i.e. the term "natural" is not meant to exclude the possibility that the property is exemplified by societal phenomena (see e.g. Sawyer 2002, p. 548).

7 Again (cf. note 3), many of the explanatory holists here do think that the relevant social predicates do figure in laws at the social level and hence that the predicates express genuine properties (e.g. Kincaid 1990/1994; Fodor 1997; Sawyer 2003, 2005, 2012). One issue this raises is about the nature of these putative social properties, if they are irreducible as types. A natural thought is that they are functional properties. However, Sawyer explicitly says that he does not want to commit himself to some sort of functionalism. What is essential for the explanatory holistic argument, he maintains, is merely that social properties are multiply realizable (Sawyer 2002, p. 546).

8 Fodor concurs (at least if the identity condition is formulated as a material conditional). He says: "if every event is the instantiation of a property [...]: two events will be identical when they consist of the instantiation of the same property by the same individual at the same time" (Fodor 1974/1994, p. 689).

9 Sawyer explicitly writes: "the relation between social events and individual events is one of token identity but not of type identity" (Sawyer 2002, p. 542). And Fodor says: "the bridge statements express true token identities" (1974/1994, p. 696). Strictly speaking, Fodor goes beyond ontological individualism; he is attracted to token physicalism: "Token physicalism is simply the claim that all the events that the sciences talk about are physical events. [...] If science is to be unified, then all such [special science] taxonomies must apply to the same things. If physics is to be basic science, then each of these things had better be a physical thing." (Fodor 1974/1994, p. 689, 698, emphasis in original) 
cal. ${ }^{10}$ (I should perhaps add here that I take the identity relation to be "absolute" (see e.g. Wiggins 2001, Ch. 1), not "relative" à la Geach (1980/1997). On the classical, absolute sense of identity, the issue whether certain objects/events/properties are identical does not hinge on how we refer to, conceptualize, or individuate these objects/events/properties: either the identity relation obtains between the referents or it does not.)

Secondly, the bridge principles explicitly defended by the Fodorian explanatory holists express token-token identities between objects. According to the bridge principle schema stated above (see also Sawyer 2002, p. 550), the object $x$ which, on a specific occasion, satisfies predicate " $S$ " is numerically identical with the object $x$ satisfying one of the $P$-type predicates. As Fodor puts it: " $S$ and $P$ predicates apply to the same things" (1974/1994, p. 688). That it is the same object that satisfies the relevant predicates follows from the use of the same variable on the left-hand side and the right-hand side of the biconditional. No doubt, within the context of the explanatory individualism/holism debate, the idea is that, in an individualistic science, $x$ will be referred to as a plurality or sum of interrelated individuals (cf. Sawyer 2002, p. 550); but the position our explanatory holists are committed to is that it is this plurality or sum of interrelated individuals which, on the occasion in question, satisfies (or jointly satisfy) the relevant secondary science predicate " $S$ ". Thus, if the secondary science predicate in question is, say, "is an organization", then on this scheme the relevant plurality or sum of individuals is an organization; and the organization that they are identical with is the very organization referred to on the left-hand side of the biconditional; consequently, if the particular organization has a proper name, then on this picture the relevant individuals are the referent of the name of the organization.

Thirdly, the Fodorian explanatory holists overtly advocate token-token identities between social and individualistic objects. For example, Harold Kincaid writes that "Individuals exhaust the social world in that every entity in the social realm is either an individual or a sum of such individuals" (Kincaid 1986/1994, p. 499), a view which is more or less restated in a more recent publication of his: "We can hold that any particular social entity at a given time and its causal powers are token identical with the sum of individuals composing it" (Kincaid 2009, p. 731). Daniel Little concurs: "it might well be true that each instance of a social kind - for example, a state structureis identical with an ensemble of individual actors having certain properties" (Little 1991, p. 188). Little also says:

The ontological thesis of methodological individualism (MI) holds that all social entities are reducible without remainder to logical compounds of individuals. On this account, social entities are nothing but ensembles of individuals in various relations to one another. A university is nothing but the individuals who are

\footnotetext{
10 Note that according to the above identity condition for events, the properties involved must be identical too. But as we have just seen, the Fodorian explanatory holists explicitly deny that the properties involved are identical, at least as types. Thus, in order for their position to be coherent, they must be construing the properties involved in token events as particulars—i.e., as something like "tropes"—although they never explicitly make this qualification (cf. note 5). I will return to this issue in Sect. 7.
} 
involved in university activities. [... ] The ontological thesis is manifestly true (ibid: $183-184)^{11}$

And Keith Sawyer endorses the view that "sociological objects and properties are nothing but combinations of the individual participants and their properties" (2002, p. 537).

In the next three sections I will argue-against both Fodorian explanatory holists and explanatory individualists (see Zahle 2003 for a fairly recent defense of explanatory individualism) — that bridge principles expressing token-token identities between social objects (as they are now described in social sciences) and pluralities or sums of interrelated individuals must be rejected. Since explanatory individualists and Fodorian explanatory holists alike endorse reductive token-token identities between social and individualistic objects, I will refer to them all as Social Object Reductionists or SORs. The usual term, "ontological individualists", is ambiguous, since as well as referring to SORs (see e.g. Bhargava 1992, p. 19; Schmitt 2003, p. 2) it can be applied to social object eliminativists (see e.g. Tuomela 1995, Ch. 9; Schmitt 2003, p. 2). Note also that some philosophers (e.g. Epstein 2009, 2015) apply the term to certain social object realists who deny that social objects can be identified with individuals. Thus, I think the term "ontological individualist" has become too inexact to be useful.

\section{Against reductive token-token identities I}

To keep things manageable, in this section I will focus on a single kind of case, but as I will occasionally indicate, the points made can be generalized and apply to the sample cases mentioned by the Fodorian explanatory holists discussed in Sect. 3.

Under the hypothetical assumption of social object realism, consider a particular object, $a$, falling under the ubiquitous social science sortal predicate "is a team". ${ }^{12}$ Let $a$ be composed of $n$ members (where $n>1$ ). Can $a$ be identified with an entity or a plurality of entities available to the SORs? Well, obviously $a$ cannot be identified with the members individually. The members $\left(m_{1}, \ldots, m_{n}\right)$ are distinct $\left(m_{1} \neq m_{2}\right.$, etc.), so if $a$ were identified with the members individually $\left(a=m_{1}, a=m_{2}, \ldots\right)$,

\footnotetext{
11 In his new book (Little 2016) — published after the main bulk of this paper was written — Little no longer puts forth such strong claims. Now, he is content speaking of "micro-foundations" (e.g. p. 82) and defending the view that "social entities supervene on socially situated actors" (ibid). However, as I argue in detail in Sect. 7, if token-token identities are given up, multiple realization is no longer relevant to the explanatory individualism/holism issue.

12 In the social sciences a team-sometimes called a "social group" (see e.g. Giddens et al. 2014, pp. 135-136) - is generally taken to be a group of people united by a common purpose. The notion is a central one; various social science entities are thought to be teams. Some social scientists would probably want to classify all of the entities referred to by the Fodorians in Sect. 3 as teams. For example, in my old textbook on economics, football teams are mentioned as obvious and paradigmatic examples of teams, but the authors go on to say: "You can also think of an entire firm as being a team" (Parkin and King 1995, p. 236; see also Giddens et al. 2014, p. 139). Note also that the predicate "is a group" itself is a muchemployed social science predicate. However, I will not focus on it, since it is occasionally used, e.g. in demography, merely for a number of individuals who happen to share some arbitrary property but who in other respects might be totally unrelated (the individuals in question may not even be aware of each other). Again, teams are supposed to be unified-internally integrated - groups. Arbitrary, non-unified "groups" might be more easily identified with pluralities or sums of individuals (see e.g. Giddens et al. 2014, p. 136).
} 
the transitivity of identity (for all $x, y$ and $z$, if $x=y$ and $y=z$, then $x=z$ ) would have to be given up.

Can $a$ be identified with the members collectively - that is, with the plurality, the $m$ s $\left(=m_{1}, \ldots, m_{n}\right)$ (cf. Schmitt 2003, p. 4; Ritchie 2013, pp. 260-262)? Defending such a view amounts to endorsing the controversial thesis that composition is identity; that is to say, the thesis that when some entities, the $x \mathrm{~s}$, compose an object $y$, then $y=$ the $x$ s (for general discussion of composition as identity (CAI), see e.g. Baxter 1988a, b; Lewis 1991; Cotnoir 2014). CAI faces a well-known difficulty, however. The standard objection (see e.g. Lewis 1991, p. 87; Schmitt 2003, p. 4; Ritchie 2013, pp. 260-261; my 2014a) is that a single object $y$ (such as a team) cannot be identified with a plurality of objects, the $x \mathrm{~s}$ (the members), on the simple ground that $y$ is one and the $x$ s are many; for how could one and the same thing both be one (i.e. not many) and many (i.e. not one)? As Bertrand Russell wrote already in 1903:

To say that $A$ is one seems to amount to much the same as to say that $A$ is not of the form ' $A_{1}$ and $A_{2}$ and $A_{3}$ and ...' [...] It is important to realize that a whole is a new single term, distinct from each of its parts and from all of them: it is one, not many, and is related to the parts, but has a being distinct from theirs. (Russell 1903, p. 70, 141)

It is striking that SORs have not addressed this classical objection. ${ }^{13}$ But quite apart from this difficulty, I think there are further, and to my mind graver, objections to the thesis that team $a$ can be identified with its members, the $m \mathrm{~s}$, and it is to these that I now turn.

The first additional difficulty is this. The formation of a team (an organization, an institution, a state ...) is in the social sciences generally not described as a qualitative change-that is, in terms of a pre-existing object changing its properties so that it (that very thing) turns into a team. Instead it is described-as philosophers would put it — as a substantial change: in reporting that a team has been formed, social scientists usually say or imply that a new, i.e. additional, object has been created. ${ }^{14}$ Turning,

\footnotetext{
13 Perhaps they simply rely on Gottlob Frege here, who famously held that "counts" of objects must be relativized to sortals or concepts and that such relativized counts allow us to count a single/many thing(s) as "both" one and many. He asserted, for example: "While looking at one and the same external phenomenon, I can say with equal truth both 'It is a copse' and 'It is five trees', or both 'Here are four companies' and 'Here are 500 men'. Now what changes here from one judgment to the other is neither any individual object, nor the whole, the agglomeration of them, but rather my terminology." (Frege 1884/1980, p. 59; see also Baxter 1988b, 2014; and Locke 1689/1997, pp. 287-288) Given the intimate tie between the concept of counting and the concept of identity (see e.g. Hawthorne 2003, p. 111), it is unclear, however, whether this kind of view is compatible with the notion that identity is absolute and not relative. In any case, the additional difficulties discussed in the text apply irrespective of whether counting is sortal relative.

14 See e.g. Tuckman's influential (1965/2001) paper on group development, where he says: "The group becomes an entity by virtue of its acceptance by the members, their desire to maintain and perpetuate it, and the establishment of new group-generated norms to insure the group's existence" (Tuckmann 1965/2001, p. 70, my emphasis). Notice that Tuckman is using "group" in the sense of "team" discussed in note 12 above, not in the arbitrary collection sense. Consider also the large hands-on literature on team building, exemplified by Harvard Business School's Creating Teams with an Edge (2004). Often Tuckman's theory is applied in these writings. In juridical contexts the formation of objects such as corporations is often described in terms of creation. John Searle mentions the following example from the California Code: "Section 200A: 'One or more natural persons, partnerships, associations or corporations, domestic or foreign, may
} 
then, to our team $a$, I assume that social scientists would hold that before the members $m_{1}, \ldots, m_{\mathrm{n}}$ decided to form this team, there was no pre-existing entity ready, as it were, to become a team, although each individual $m_{1}, \ldots, m_{\mathrm{n}}$ existed at the earlier time. They would deny that there already existed an entity - the referent of the name " $a$ "- that would eventually satisfy the predicate "is a team". But if $a$ is identified with the $m \mathrm{~s}$, as suggested by the SORs, then $a$ must be said to have existed before the team was formed (because the $m$ s predate the formation of the team), and consequently it must be said that $a$ became a team. Thus, the identification of $a$ with the $m$ s would result in a substantial revision of the current notion of a team, and therefore also of the social science theories in which this notion is embedded. Note also that similar considerations apply, mutatis mutandis, to the dissolving of teams.

To render " $a$ did not exist before the formation of the team" compatible with $a$ being ontologically reduced to the $m \mathrm{~s}$, SORs might propose that the identity statement " $a=$ the $m \mathrm{~s}$ " (and bridge principles in general) should be read as being implicitly governed by a time clause specifying the interval $t$ during which the identity holds (at $t: a=$ the $m s$ ). The idea would be that it is only when the $m$ s have certain attitudes or are suitably interrelated that they are identical with $a$, and that $a$ exists only when the $m \mathrm{~s}$ have such attitudes or are so interrelated (so, before $t$ : the $m \mathrm{~s} \neq a$ ). ${ }^{15}$

However, this suggestion involves the idea that the identity relation holding between $a$ and the $m \mathrm{~s}$ is a temporary relation, and that idea is refuted by the following consideration: according to the conceptual scheme we are considering, it is true of the $m \mathrm{~s}$ (e.g. at $t$, when the one-many identity allegedly holds) that they existed before $t$, but it is not true of $a$ (at $t$ ) that it existed before $t$. Given Leibniz's Law-which says that if $x=y$ then whatever is true of $x$ is true of $y$, and vice versa-we must conclude that $a$ is not (at $t$, nor at any other time) identical with the $m \mathrm{~s} .{ }^{16}$ Thus, consistent SORs (who accept Leibniz's Law and who insist that $a$ is identical with the $m \mathrm{~s}$ ) cannot avoid

Footnote 14 continued

form a corporation under this division by executing and filing articles of incorporation.' Section C: 'The corporate existence begins upon the filing of the articles [...]"' (Searle 2010, p. 97). Searle then goes on to say: "The law does not say that some pre-existing X becomes a corporation; rather, it says that a corporation may be formed. It says that the performance of these written speech acts- 'executing and filing articles of incorporation' - counts as the creation of a corporation" (Searle 2010, p. 98; see also MacCormick and Weinberger 1986, p. 52; Cole 2014; my 2014c; cf. also Uzquiano 2004, p. 136).

15 Sociologist Elder-Vass occasionally (e.g. 2010, pp. 21-25) appears to defend a view like this (but see Elder-Vass 2014 for a retraction/disclaimer).

16 We can modify Leibniz's Law so that it straightforwardly applies to one-many identities: $(\forall x)(\forall y y)$ $(x=y y \rightarrow(\Phi x \equiv \Phi y y))$. Moreover, the argument goes through even if a temporally relativized version of (the one-many version of) Leibniz's Law is adopted: $(\forall x)(\forall y y)(\forall t)$ (at $t: x=y y \rightarrow$ (at $t: \Phi x \equiv$ at $t$ : $\Phi y y)$ ). Just substitute "existed $n$ units of time ago" (for some appropriate unit of time and choice of $n$ ) for $\Phi$. (For a book-length defense of temporary identity, see Gallois 1998; for persuasive criticism of the idea, see Sider 2001, pp. 165-176.) Moreover, as is well known, Kripke (1980) has argued forcefully that identity holds of necessity between its relata; that is, it is not a relation which could have failed to hold between them. Carrying over his line of reasoning to plurals and to intra-worldly cross-time evaluations of identity statements, we get the following: Let " $a$ " and "the $m \mathrm{~s}$ " be modally and temporally rigid designators; then, if " $a=$ the $m \mathrm{~s}$ " is true at some time in some world, " $a=$ the $m \mathrm{~s}$ " is true in all worlds and at all times (where the rigid designators refer). This Kripkean consequence has ramifications for the possibility of membership-change, as I discuss in the main text below. 
the revisionary consequence that $a$ existed before $t$ even if they (redundantly) qualify their identity statement " $a=m$ s" with a time clause.

I now turn to a second additional difficulty with identifying $a$ with the $m \mathrm{~s}$, and one which I think is even more serious than the first. This is that, with this identification, $a$ turns out to be an entity which cannot change members. Here is why:

Let the $m \mathrm{~s}$ be $m_{1}, m_{2}$ and $m_{3}$ (let "the $m \mathrm{~s}$ " rigidly denote these individuals). There is no time at which these individuals, the $m \mathrm{~s}$, exist and yet one or more of $m_{1}, m_{2}$ and $m_{3}$ does not exist. The $m$ s are identical with $m_{1}, m_{2}$ and $m_{3}$ at every time at which the $m$ s exist. Now assume that $a=$ the $m$ s (and let " $a$ " be a rigid designator). Then, since the $m \mathrm{~s}$ are identical with $m_{1}, m_{2}$ and $m_{3}$ at every time at which the $m$ s exist, and since $a=$ the $m \mathrm{~s}$, it must be the case that $a$ is identical with $m_{1}, m_{2}$ and $m_{3}$ at every time at which $a$ exists. That is, $a$ cannot change members. ${ }^{17}$

The trouble with this conclusion is, of course, that the social sciences currently describe teams (organizations, states, ...) as entities that can change their members. It is a commonplace in the social science literature that people can join and leave teams without destroying the team (at least if the team consists of more than two members, see Giddens et al. 2014, pp. 142-143). Thus this kind of token-token identity cannot be upheld, on pain of very substantial revision of the notion of a team. ${ }^{18}$

Can the problems discussed above be circumvented if $a$ is identified, in line with Kincaid's suggestion (2009, p. 731), with the mereological sum of the $m \mathrm{~s}, s_{m s}$, rather than the mere plurality, the $m s$ ? Mereological sums are supposed to be singular entities made up of their summands $(a+b+c \ldots)$, in contrast with mere pluralities which are (typically) simply many entities $(a, b, c, \ldots)$ (see e.g. Linnebo 2012). More specifically (following Simons 1987, p. 184, Fine 1999, p. 63, and Lowe 2009, pp. 93-94), I take $s_{m s}$ to be a concrete, singular entity which exists when, and only when, all of the $m \mathrm{~s}$ exist. $^{19}$

So, can the problems discussed above be circumvented if $a$ is identified with $s_{\mathrm{ms}}$ ? Well, since mereological sums of distinct objects are understood as singular wholes, or units, the one/many issue does indeed dissolve. Unfortunately, however, the rest of the problems remain intact. Team $a$ must still be said to have existed before the formation of the team, because $s_{\mathrm{ms}}$ existed before this formation (again, $s_{\mathrm{ms}}$ co-exists with the $m \mathrm{~s}$ ). And $a$ still cannot change its members (pace Ritchie 2013, p. 263), because $s_{\mathrm{ms}}$

17 This sort of argument can be found already in Merricks's (1999). Merricks argues that CAI entails mereological essentialism. His focus is on modality, however, whereas the argument just presented discusses intra-worldly temporal change of members (see also Ritchie 2013, p. 262; List and Spiekermann 2013, p. 633; Uzquiano 2004, pp. 138-141, although he does not address CAI but reduction of social objects to sets).

18 Is not membership change incompatible with Leibniz's Law? No-there are various ways membership change can be rendered compatible with LL (see e.g. Lowe 1988; my 2007, 2010; Rychter 2009).

19 Mereological sums are supposed to be concrete singular entities that exist in space and time, in contrast with sets which are abstract (platonic) singular entities. Since sets are abstract, spatially located social objects cannot be identified with them (pace Effingham 2010) — see my (2014c) for discussion of this point. Notice that I take "sum" in the sense of Simons's SM sums (1987, p. 187) and Fine's compound sums (1999, p. 63). There is also a "disjunctive" sense of sum: such sums exist when at least one of their summands exist (cf. Simons's SU sums, 1987, pp. 183-184, and Fine's aggregative sums, 1999, p. 62). However, these latter sums are even more problematic. If $a$ were identified with a SU/aggregative sum of the $m \mathrm{~s}$, it would be necessary to claim that $a$ began to exist when the oldest of the $m$ s was born. 
cannot change its summands, the $m$ s (cf. Ruben 1985, p. 16; Simons 1987, p. 184; Uzquiano 2004, p. 137; Lowe 2009, pp. 97-98; my 2014c, pp. 544-546). ${ }^{20}$

Moreover, I think it could be questioned whether the suggested token-token identification is sufficiently reductive. As we saw in Sect. 1, purely individualistic theories should speak only of individuals and their interactions and interrelations. Furthermore, the Fodorian explanatory holists think that each token social object can be identified with an object or objects which is/are describable in a purely individualistic vocabulary (at least relative to a certain time). But if $a$ is identified with $s_{m s}$, then $a$ is identified with an entity picked out as a sum of distinct individuals, and sums of distinct individuals are themselves complex wholes or units which are composed of individuals. If sum-composition is not identity, then obviously the suggested token-token identification is only modestly reductive (which is why the one/many issue is avoided) ${ }^{21}$ Thus, I think it can be questioned that the sum maneuver is a legitimate one. True, it might be insisted that this deviation from a thoroughgoing one-many reduction is tolerable so long as SORs do not identify social objects with entities that they pick out with the help of paradigmatic social science terms. To hold that a token object $x$ falling under the social science predicate "team" is identical with a token object $y$ falling under the semi-individualistic predicate "sum of individuals" is still to be a SOR of sorts, in that the thesis conforms to a moderate kind of reductive token-token identity view. But, as I have just pointed out, the relevant token-token identification can in any case be made only on pain of revising the concept of a team in a fairly dramatic manner: teams must be allowed to pre-date their own formation and it must be denied that teams can change their members.

\section{Against reductive token-token identities II}

At this stage of the argument it might be suggested that if mereological sums are after all allowed in the reductive base, and if the SORs, moreover, adopt four-dimensionalism, the objections above can be handled. Four-dimensionalism comes in two versions: the perdurance variety and the stage-theoretic variety. Very briefly (I discuss these theories more thoroughly elsewhere: see e.g. my 2009a, 2014c), on perdurance theory (e.g. Lewis 1986, pp. 202-204), persisting individuals and objects extend in time the way they extend in space; they have not only spatial parts, but temporal parts as well. Indi-

\footnotetext{
20 Sums (of the SM or compound variety) of enduring entities may be able to change some of their proper parts (van Inwagen 2006), but not their summands (Simons 1987, p. 184; Lowe 2009, pp. 97-98). See my (2014c) for further discussion of this issue. Let me also mention here that the sum proposal is sometimes criticized on the grounds that the "part of" relation is transitive (e.g. Schmitt 2003, pp. 5-6). However, so long the membership relation (which is not transitive) is not identified with the part of relation, I see no reason to worry about the transitivity of the latter relation. Members are arguably parts of a certain special kind (they have to be agents, etc.), they are not mere parts simpliciter; see my (2014c, n. 52).

21 It is sometimes argued that mereological sums of objects are nothing over and above the objects summed, i.e. that sums display composition as identity (e.g. Baker 2007, pp. 191-194). If sums of individuals are taken to be identical with pluralities of individuals, obviously the sum move faces exactly the same problems as those discussed above.
} 
viduals and objects are cross-temporal mereological sums ${ }^{22}$ of their temporal parts, and they persist through time by having distinct temporal parts at distinct timesas the phrase has it, by "perduring" through time. In stage theory (e.g. Sider 2001, pp. 188-208), individuals and objects are not identified with cross-temporal mereological sums of distinct temporal parts. Instead, a token object/individual is identified with a single, instantaneous temporal part of such a cross-temporal sum. Individuals and objects are said to "persist"- or more technically, to "exdure"-if they have temporal counterparts existing at other times (i.e. if there are other temporal parts, at other times, that can be taken to represent the relevant particular individual/object as existing at those times).

Now, it might be claimed that four-dimensionalism allows SORs to overturn the objections levelled in Sect. 4 in the following way. In the perdurantist version, identify team $a$ with the cross-temporal sum consisting of those temporal parts of the relevant individuals which lie within the temporal boundaries of $a$. This cross-temporal sum is a single thing and not many, and hence the one/many objection does not apply. Moreover, this sum begins to exist at the time when the team is (allegedly) formed and ceases to exist when the team is (said to be) dissolved. Consequently, the first additional objection (from incompatible temporal properties, discussed in Sect. 4) is avoided. Moreover, where $a$ is described as changing its members over time we can simply subtract from the sum (in which case a new sum is picked out, strictly speaking) those temporal parts of the relevant departing individuals that exist after the departure; and we can add those temporal parts of the relevant joining individuals that exist from the time at which these latter individuals join the team up to the time when they either leave the team or the team is said to dissolve. ${ }^{23}$ In this way the second additional difficulty (having to do with membership change) is avoided.

In the stage-theoretic version, identify $a$ with some arbitrary instantaneous temporal part of the cross-temporal sum discussed in the perdurance account. The rest of the temporal parts of this sum will then be $a$ 's temporal team-counterparts. The difficulties discussed in Sect. 4 are then avoided in the following way. First, the relevant temporal part that $a$ is identified with is one and not many, so the one/many objection is avoided. Secondly, this temporal part that $a$ is identified with "began to exist", qua team, at the time when its first team-counterpart existed, and it "will cease to be", qua team, at the time when its last team-counterpart exists (cf. Sider 2001, pp. 200-201), so the first additional difficulty is avoided. Thirdly, qua team the relevant temporal part "changes members over time" if some of its team-counterparts are composed of individuals who are not temporal person-counterparts of the individuals of which it is itself composed.

A sceptic might object to these token-token identifications on the grounds that social scientists rarely, if ever, speak of teams as perduring or exduring through time (although some philosophers do, see e.g. Copp 1984 and my 2014c). In response,

\footnotetext{
22 In the context of four-dimensionalism, "mereological sum" is to be understood in terms of classical extensional mereology; see e.g. Leonard and Goodman (1940), Goodman (1966), Lewis (1986), Simons (1987) and Sider (2001).

23 The underlying general idea is roughly that SORs of a perdurantist persuasion can hold that an arbitrary individual $i$ is a member of $a$ at time $t$ iff the temporal part of $i$ existing at $t$ is a part of the temporal part of $a$ that exists at $t$.
} 
SORs of a four-dimensionalist persuasion might argue that even if social scientists tend to presuppose a commonsense endurance theory of persistence (according to which objects persist by being wholly present at distinct times as numerically the same entity, see Johnston 1987), this presupposition need not be a hindrance to the kind of ontological reductions under consideration so long as the social scientists do not, in their theorizing, explicitly deny that social objects exdure or perdure, and do not say things which are incompatible with such reductions.

As far as I know, social scientists are not in the habit of denying that social objects perdure or exdure (presumably because most are unaware of these notions). On the other hand, it may well be that their use of certain "life-span" counterfactuals (e.g. "If it hadn't been for Gorbachev, the Soviet Union wouldn't have dissolved in 1991"24), is incompatible with at least perdurantism (for discussion, see van Inwagen 1990 and my 2009a). Here I will not tackle this controversial issue. Rather, I want to point out that there is another objection to the token-token identity view (in addition to those discussed in Sect. 4), which is, as far as I can see, irresolvable even if the social objects of current social science can be coherently conceptualized as perduring or exduring (which can be questioned). ${ }^{25}$

In the social sciences-but also in colloquial speech, and notably in law-social objects such as teams, organizations and corporations are characterized as nonextensional objects, in the sense that distinct such objects can have the same members at the same time. The issue of non-extensionality has been widely noted by philosophers (e.g. Quinton 1975-1976; Ruben 1985, p. 15; Simons 1987, p. 168; Gilbert 1989, pp. 220-221; Uzquiano 2004; Ritchie 2013; Epstein 2015, p. 139), but to my knowledge it was the law professor William Jethro Brown who, way back in the beginning of the twentieth century, first highlighted the phenomenon and explained why it is problematic for the SORs, although he is seldom credited for this in the literature.

Brown wrote:

The very same persons who have registered themselves as one company may also register themselves as another and quite distinct company. If the corporation were identical with the sum of its members they would be one company, but the law holds them two. (Brown 1905/2008, p. 262)

Again, the extensionality problem generalizes to other social objects such as reading groups, football teams and orchestras: for example, if a reading group $a$ and a football team $b$ have the same members at time $t, a$ and $b$ cannot be reductively identified with their at $t$ common members-or with the enduring/exduring sum of these membersbecause that would infringe the transitivity of identity: in colloquial speech and in the social sciences, such social objects are treated as distinct objects. ${ }^{26}$

\footnotetext{
24 For a book packed with such counterfactuals, see Gerner (2015).

25 I mentioned this problem already in my (2014c), but I am now convinced that there is no satisfactory individualistic solution to it.

26 David Wiggins famously argued that no two objects of the same kind can be in the same place at the same time (Wiggins 1968, p. 93). But interestingly, theorizing in the social sciences disagrees. As Katherine Ritchie (2013, p. 259) points out, distinct groups (what I am calling teams) are allowed to be in the same place at the same time.
} 
Note that it is of no help invoking perdurantism here, because, as Gabriel Uzquiano points out, social objects which are treated as distinct in the social sciences can have the same members at all times of their existence, at least in principle (see also Ritchie 2013, p. 263).

The identification of an organization with the fusion [sum] of temporal parts of all of its members will not be able to distinguish two organizations that happen to coincide in all of their members for their entire duration. There could have been, for example, a club whose members happened to coincide at every time at which the club exists with the justices then serving as Supreme Court Justices. [...] The mereological fusion of temporal parts of members of this club while members would exactly coincide with the fusion of temporal parts of Supreme Court Justices while Supreme Court Justices, and thus the Supreme Court would be identical with the club by the lights of temporal parts theorists. (Uzquiano 2004, pp. 146-147)

The lesson, I take it, is that if ontological reduction is to be successful, token social objects must be identified with something more than the mere plurality or sum of their suitably interrelated members (or their suitably interrelated temporal parts), because distinct social objects can be co-membered. That is, if token-token reductions are to be successfully carried out, social objects must be taken to have parts or constituents that are disjoint from their members.

But what could these extra constituents be? I see only one plausible candidate: the suitable relations that relate the members. ${ }^{27}$ More specifically, SORs could take particular social objects as being identical with Armstrongian states of affairs consisting of individuals/temporal parts being interrelated in certain appropriate ways (see Armstrong 1997, Ch. 8). So, in the case of two permanently coinciding social objects $a$ and $b$, SORs could say something like this: $a=R$ (the $m \mathrm{~s}$, the $m \mathrm{~s}$ ), and $b=R^{\prime}$ (the $m \mathrm{~s}$, the $m \mathrm{~s}$ ). (This should be contrasted with saying merely: $a=$ the $m \mathrm{~s}$, or $a=s_{m}$, or $a=$ the cross-temporal sum of the relevant temporal parts of the $m \mathrm{~s}$ (and likewise for $b)$ ). The idea would be that although $a$ and $b$ do not differ with respect to membership or individual composition, they differ with respect to how the members (or their temporal parts) are interrelated $\left(R \neq R^{\prime}\right)$. For example, as members of $a$, the $m$ s may have certain (joint) commitments and obligations to each other, while as members of $b$ they have other commitments and obligations (cf. Gilbert 1989, pp. 220-221). So, although the $m \mathrm{~s}$ are interrelated by both $R$ and $R^{\prime}$ (which may be sets/sums of relations), $R$ does not enter as a constituent of $b$, and $R^{\prime}$ does not enter as a constituent of $a$, and this ensures that $a$ and $b$ are distinct objects. ${ }^{28}$

\footnotetext{
27 If some social science objects include material parts, e.g. certain artifacts, then similar coextensionality problems arise for them. For example, there seems to be nothing incoherent about the claim that two government departments could share employees_-people having double duties_-and buildings/offices at all times. Thus, on a reductive account, the differentiating factor would have to be something beyond these individuals and their offices_again, presumably the various relations obtaining among the individuals.

28 This proposal has similarities with the "structuralist" conception of groups (teams) set out by Schmitt (2003, p. 6) and Ritchie (2013). See also Fine (1999) and Koslicki (2008), although they do not primarily address social objects.
} 
It might be hoped that this states of affairs maneuver will take care of not only the non-extensionality issue, but the other problems discussed in Sect. 4 as well. Will it? Certainly, the first two problems dissolve. States of affairs are unitary particulars distinct from their components (cf. Armstrong 1997, pp. 119-123), and so the one/many issue is avoided - but obviously at the cost of introducing complex wholes partly consisting of several individuals. (Again, it can be questioned that this is a legitimate move; see footnote 1 and the discussion of "sum of individuals" in Sect. 4; cf. also Schmitt 2003, p. 6.) Secondly, since states of affairs begin to exist when the objects they partly consist of instantiate the properties or relations at issue, the first additional problem is also avoided. Thirdly, if some version of four-dimensionalism is adopted, the second additional problem, having to do with change, is circumvented. States of affairs cannot endure through changes in their constituents, but given that persisting and changing social objects are taken to consist of cross-temporal sums of distinct states of affairs that exist in succession, the problem can be handled in the standard four-dimensionalist manner (cf. Armstrong 1997, pp. 99-107).

In these respects the states of affairs move looks promising. However, I strongly doubt that a SOR, even of a four-dimensionalist stripe, would in the end want to say that social objects literally consist of, or are partly composed of, the relations in question. (To be sure, nominalists will not wish to say that social objects are composed of relations. In general their aim is to reverse the direction of analysis: typically they hold that relations can be analyzed in terms of set theoretical constructions of objects.) The relevant relations are not common or garden physical relations such as spatial proximity or chemical bonding (cf. Elder-Vass 2010, pp. 199-202). Rather, they are typically of a deontic (normative) kind: commitments, obligations, rights, responsibilities, and so forth, that obtain among the members (or, fundamentally, among their temporal parts) (see e.g. Gilbert 1989). Now, notoriously, relations are as such elusive entities, more so than monadic, intrinsic properties. For example, they are generally very difficult to locate spatially. ${ }^{29}$ "Deontic relations" (as we may call them) are certainly no exception. Commitments, rights and obligations are highly abstract phenomena whose ontological status is exceedingly obscure. Moreover, to fulfil their supposed role here they must, first, be taken to be somehow external to the members in question, since if they are regarded as (reducible to) mere internal psychological states of the individuals then they are not entities disjoint from the members in question and thus cannot serve as extra constituents of teams. Secondly, they must be substantial enough - in spite of their ostensibly abstract nature-to serve as genuine parts or constituents. Thus, for the states of affairs move to work, deontic relations cannot be treated as mere so-called "internal" relations (cf. Heil 2012, pp. 145-150). I strongly doubt that SORs would want to reify these relations in the strong way required. Looking at what SORs actually say, we do find statements to the effect that people form a social object when they are interrelated in certain ways (e.g. Little 1991, p. 183; Sawyer 2002, p. 548; Elder-Vass 2010, pp. 20-26); but in their regimented formulations SORs do not quantify existentially over these relations, nor do they claim that the relations enter

29 See e.g. Russell (1912/1980, p. 56) and Heil (2012, pp. 140-141). Armstrong is also at loss to explain how they can be spatially located (see Armstrong 1989, pp. 98-99). Intrinsic properties, on the other hand, are generally taken to be located where their subjects are. 
into the objects as literal parts or constituents. ${ }^{30}$ Rather, such statements seem merely to the express the view that relations (whatever their nature) have to be mentioned in the composition conditions for social objects ${ }^{31}$ or in the satisfaction conditions for social sortal predicates. ${ }^{32}$

Consequently, I strongly doubt that the states of affairs option, with its reification of deontic relations as literal parts or constituents of social objects, would be seriously entertained by the token-token identity theorists. SORs aim to make social objects ontologically transparent and the states of affairs proposal (as applied to social objects) frustrates this goal. Thus, in what follows, I will ignore this option. I therefore conclude that the objection from co-membered social objects is an insurmountable hurdle for token-token identity theorists, even if social objects can be coherently construed as perduring or exduring over time so that the additional difficulties discussed in Sect. 4 are circumvented.

\section{The emerging bridge principles}

Given the difficulties with reductive token-token identities between social and individualistic objects pointed out in earlier sections, I conclude that the Fodorian explanatory holists' view that the emerging bridge principles generally will be of the form discussed in Sect. 3 ought to be rejected. Remember that they defend the claim that the bridge principles typically will be of the following form (where the object $x$ satisfying " $S$ " is the same object(s) $x$ that satisfies " $P_{1}$ " or " $P_{2}$ " or " $P_{3}$ " etc.):

$$
S x \equiv P_{1} x \vee P_{2} x \vee \ldots \vee P_{\mathrm{n}} x
$$

Instead, the reasoning of Sects. 4 and 5 suggests that the relevant bridge principles often will have roughly the following structure (where " $x$ " is a singular variable, " $y y$ "

30 Quite the contrary. Dave Elder-Vass, for example, says: "The claim that societies are composed of relations rather than individuals, however, seems to me to confuse the issue. It is worthwhile in this context to revisit the application of the same principles to natural science. Molecules, for example, are composed of atoms, but not random, unrelated collections of atoms; they exist only as a result of stable and systematically organised inter-relations between the atoms that compose them. Those relations constitute the structure of the molecule, while the parts of the molecule are the atoms themselves. There is no obvious reason why we should not treat social entities in a parallel way. [...] it is one thing for the latticework of relations to constitute structure (i.e. the mode of organisation), and quite another for those relations to be seen as the parts of higher-level wholes" (Elder-Vass 2010, p. 22). See also Cameron (2014, pp. 103-105) for general criticism of the idea that arrangements and relations are literal parts of complex wholes.

31 As I argued above in Sect. 4, such a notion of restricted composition seems to commit SORs to contingent or temporary identity - a consequence which is in conflict with Leibniz's Law.

32 Here it should be noticed that in cases of institutional sortal predicates such as "is a government", "is a board of directors" and "is a committee", arguably relations to external individuals (i.e. to non-members) and to laws have also to be invoked in the relevant satisfaction conditions (see e.g. Currie 1984; Searle 1995; Hindriks 2008; Epstein 2009, 2015; my 2014c). If such additional relations are taken to be literal parts of the satisfiers of the predicates in question (i.e. of governments, boards of directors and committees), then such social objects become highly inflated entities with various abstract parts diffused over society. Clearly, this is not in line with how such predicates are actually used in the social sciences, and thus such reductions cannot be coherently made. (Such reductions would make the extrinsic properties expressed, e.g. being a government, intrinsic to the objects in question by expanding the relevant objects.) 
is a plural variable, " $S$ " is a monadic social sortal predicate [such as "is a team"], and " $R$ ", “ $R$ "”, ,.., are $n$-place predicates from an individualistic science [e.g., various variants of "are jointly committed to"] taking plural terms as arguments): ${ }^{33}$

$$
S x \equiv R(y y, y y) \vee R^{\prime}(y y, y y) \vee \ldots \vee R^{\prime \prime}(y y, y y)
$$

Such bridge principles involve Nagelian mere equivalences (with plural variables and disjunctions added: see Sect. 2); they neither express nor entail token-token identities between objects. Indeed, as I have argued above, if $S=$ is a team, then: for all $x$ and all $y y$, if $S x$, then $x \neq y y$ (and similarly if " $S$ " stands for "is an organization", "is a bureaucracy", "is a church", etc.).

\section{Consequences for the multiple realizability argument}

The arguments of Sects. 4 and 5 seem to force upon us the view that many of the social objects of current social science are (if they exist) entities distinct from (sums of) interrelated individuals / temporal parts of individuals. Such social objects can at most be taken to be exhaustively, but non-extensionally, composed-or constituted of sums - of suitably interrelated individuals (composition is a many-one relation, while constitution is one-one relation), where composition/constitution is not identity but some weaker relation, plausibly some kind of grounding, ontological dependence or determination relation (see e.g. Wiggins 1968; Baker 2007; Lowe 2009; Schaffer 2009, 2016; Cameron 2014; Epstein 2015). (I do not say some kind of supervenience relation, because supervenience is usually defined as a relation holding between sets of properties, see e.g. McLaughlin and Bennett 2011; here I am concerned with objects.) And if the token-token identity thesis for social and individualistic objects fails, theory reduction in the strong sense cannot be achieved (see Sect. 2).

What are the ramifications for the multiple realizability argument for explanatory holism (Sect. 3)? Well, let us start by asking what it means for a property to be realized in something. Philosophers often speak of property realization, but they rarely explain in detail what this is supposed to mean (this goes for the Fodorian explanatory holists as well) (see e.g. Bickle 2013). However, I see two possible interpretations of this notion in this context, one loose and one more specific.

The loose reading is simply that the property in question-call it $S$ - is instantiated or exemplified somehow or other by an object or a plurality of objects. The thesis of multiple realizability will then assert, if it is to be non-trivial, that $S$ can be exemplified by distinct objects with relevantly distinct properties, or by objects standing in rele-

\footnotetext{
33 In many cases, such bridge principles are no doubt simplistic. For example, as pointed out above (note 32), in many cases reference to external relata (i.e. to individuals not included as parts within the thing that satisfies " $S$ ") must be incorporated-e.g. in cases of governments, boards of directors, etc. (see e.g. Currie 1984; Searle 1995; Hindriks 2008; Epstein 2009, 2015; my 2014c). Moreover, it may be that individualistic sciences do not have to quantify over pluralities $(\forall x x, \exists y y)$. This issue hinges partly on whether predicates such as "jointly committed to" and "count X as" are distributive or collective (see e.g. Hovda 2014 for explanation of these terms). For a controversial suggestion that they are distributive (which would mean that ordinary singular quantifiers could be used), see Searle (1990/2002; 1995, pp. 23-26).
} 
vantly different kinds of interrelation. ${ }^{34}$ Notice that this loose conception of multiple realizability is compatible both with the endorsement of token-token identities for events and with the rejection of such identities: token instances of the multiply realizable property $S$ need not be identified with token instances of properties or relations described by the primary science.

The specific reading of a property being realized-given the propounded thesis of token-token identities for events (see Sect. 3), a thesis which is supposed to be compatible with properties being multiply realizable - is that a specific token instance (presumably, something like a "trope") of the type property $S$ is numerically identical with a specific token instance of a distinct type property $P$ (or is numerically identical with a (plurality/sum of) token relation(s) of type $R)^{35}$ which is exemplified at the time in question by an object or a plurality of objects. This specific reading is in line with the common view that properties are "realized" in the first instance by properties (see e.g. McLaughlin and Bennett 2011), not by objects (objects "exemplify" or "instantiate" properties, see e.g. Armstrong 1989). In this latter case, the thesis of multiple realizability asserts, more specifically, that tokens of the multiply realizable type property $S$ can be numerically identical with tokens of properties belonging to distinct types $P_{1}, P_{2} \ldots P_{n}$ (see Fig. 1). In other words, it says that the relevant equivalence classes of token properties, forming distinct properties understood as types (cf. Williams 1953), intersect each other and have common token members. Thus, a single property instance of type $S$ can also be an instance of property type $P_{1}$ or $P_{2} \ldots$ $P_{n}$. (Notice that this seems to be possible only if the relevant token properties/relations are somehow complex, allowing them to resemble each other in various respects.)

I will now argue, however, that the social property being a team is not multiply realizable in any of these two senses. As before, the argument applies to other social properties such as being an organization and being a nation state.

Let us start with the first, loose sense of multiple realizability. Again, we have come to the conclusion that a team (of the kind postulated in current social science)

\footnotetext{
34 If multiple realizability meant merely that the property can be exemplified (synchronically) by distinct objects, it would be fairly uninteresting. Properties understood as types are generally thought to be such that they can be multiply exemplified by distinct objects (see e.g. Armstrong 1989). Wild disjunctions of predicates would not have to be invoked to defend multiple realizability of this very weak kind. By the compressed expression "relevantly distinct properties" I mean distinct types of properties that are relevant to the objects' exemplifying the multiply realizable property and which are exemplified at the same level as the multiply realizable property, as indicated by the bridge principle schema defended by the Fodorian explanatory holists (see Sect. 3). Thus, the fact that distinct individuals who are all hungry may have fingernails with distinct properties does not entail that the property being hungry is multiply realizable (see also Shapiro 2000). The properties of their fingernails are both irrelevant to the exemplification of being hungry and fail to be exemplified at the same level as being hungry (the person is hungry, but the properties of the fingernails are properties of proper parts of the person).

35 No doubt, if a single token property is identified with many token relations, the one-many problem returns, but now in relation to abstracta. Moreover, arguably it is a category mistake to identify properties with relations. But here I am merely trying to makes sense of "multiple realization" in the context of explicitly defended token-token identities between social and individualistic events. Presumably, the Fodorian explanatory holists will want to refer to structural properties $\left(P, P_{1}, P_{2} \ldots\right)$ which are exemplified by pluralities/sums of individuals in virtue of the individuals standing in various relations $\left(R, R^{\prime}, R^{\prime \prime} \ldots\right)$ to each another. However, they never state this explicitly and they never make clear how exactly this is supposed to work.
} 
Fig. 1 Property type $S$ being multiply realized by instances of type properties $P_{1}, P_{2}$ and $P_{3}$. Dots represent property instances or "tropes"

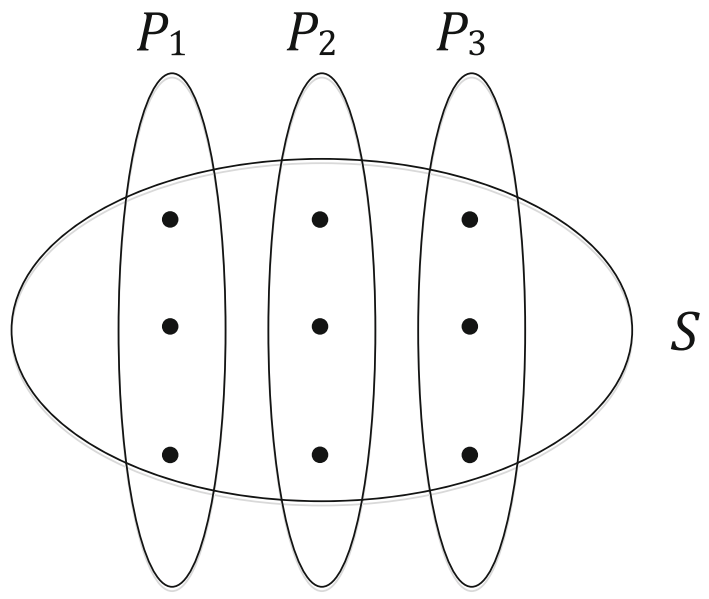

must (if it exists) be taken to be numerically distinct from interrelated individuals or sums of (temporal parts of) such individuals. (Henceforth I will ignore the sums of individuals/temporal parts, but similar remarks apply to them.) If a team is distinct from interrelated individuals, the relevantly interrelated individuals do not exemplify being a team (or, in the formal mode, do not satisfy the sortal predicate "is a team"). If they did, they would be identical with a team. But that is precisely what we have found to be untenable. Thus, it is not the case that the property being a team can be exemplified by distinct pluralities of individuals standing in various kinds of interrelation, as the token-token identity theorists maintain (see Sect. 3). And this is because the "property", as characterized in current social science theorizing, cannot be exemplified by pluralities of individuals at all. Rather, this property must be taken to be exemplified by, well, teams - and teams, as they are construed in current social science, are higher-level objects numerically distinct from, albeit composed of, interrelated lower-level individuals. ${ }^{36}$ Thus, the property being a team is not multiply realizable in the first, loose sense. In terms of the bridge principle schema defended in Sect. 6, the predicate " $S$ " (here, "is a team") on the left-hand side of the equivalence sign applies to values of the singular $x$ variable only; it does not apply to values (individuals) of the plural yy variable on the right-hand side.

No doubt, in the social sciences different kinds of team are spoken of (e.g. football teams, research teams, reading groups, committees, governments, firms, etc.). In that sense the property being a team is "multiply realizable": i.e. it is treated as a determinable with distinct determinates falling under it. But multiple realizability of this sort is clearly not what Fodorian explanatory holists are after, since the relevant determinate predicates expressing these properties are characteristic social social science predicates too (see notes 1 and 3) and thus cannot figure as $P$ or $R$ predicates. And if

36 The case is analogous to the much-discussed example of a tree and the collection of cells composing it (e.g. Wiggins 1968; Lowe 2009; Fine 2003): the cells merely compose the tree, they are not themselves a tree. 
what I have been arguing in Sects. 3-6 is correct, predicates such as "football team", "research team" etc. cannot apply to the plural yy variable in the bridge principle presented in Sect. 6. Moreover, I admit that if "realized in" is used in the very weak (and in this context confusing) sense of "grounded in", the thesis of multiple realizability holds for the kinds of social property we have been addressing, since social scientists obviously hold that the objects exemplifying these properties can be composed and structured in various ways. But notice that then we are referring to variable components and properties at some level(s) below the level of the allegedly "multiply realizable" property. The distinction between flat and dimensioned accounts of realization, put forth by Gillett (2002, 2003), is useful here: the flat accounts require realized and realizing property instances to be exemplified by the same object at the same level, while the dimensioned accounts allow that the property instances are exemplified by distinct objects at different levels of being. It is plain that the Fodorian explanatory holists are advocating a flat account of multiple realizability: they use the term "multiple realizability" within the context of a token-token ontology, and they explicitly defend bridge principles of the form presented in Sect. 3 in which the $S$ and $P$ properties are exemplified at the same level by the same object $x$. Their goal is to reject type-type identities, but dimensioned multiple realization is irrelevant to this issue: dimensioned properties are as such typically already taken to be distinct. (The latter, by the way, is why Currie's (1984, p. 353) and Epstein's (2015, pp. 31-32) apparent endorsement of multiple realizability is irrelevant to the issue of theory reductionneither Currie nor Epstein is a SOR and thus a "realizing" individualistic property and the social property it "realizes" must already be taken to be distinct by them. See Polger and Shapiro (2008) for further critical discussion of dimensioned multiple realization; see also note 34 above.)

Let us move on to the second, specific reading of "multiple realizability" (involving token-token identities between primary and secondary sciences events) described a few paragraphs back. Since this second reading of "multiple realizability" is merely a specification of the first, loose one, we can immediately infer that the property being a team is not multiply realizable in the second sense either. If a token of the property were identical with some token property (or with some plurality or sum of token relations) exemplified by (holding among) individuals at a certain time (cf. note 35 ), then the property being a team would be exemplified by these individuals at that time. But it cannot be exemplified by these individuals, because if it were they would be a team. And we have already reached the conclusion that suitably interrelated individuals cannot themselves be a team. Again, at best, suitably interrelated individuals can be taken to compose a team. As I say, then, the property being a team is not multiply realizable in the second sense. As the property is characterized in current social science, it is exemplified by changeable, nonextensional, higher-level wholes with kind-specific persistence conditions-units that are somehow entities "over and above" (i.e. not identical with) their interrelated parts/members.

The Fodorian multiple realizability argument for explanatory holism therefore fails. It relies on the mistaken idea that token social science objects, such as particular teams, bureaucracies and nations states, are identical with particular pluralities or sums of (temporal parts of) individuals. 


\section{Concluding remarks}

I have argued that the Fodorian multiple realizability argument for explanatory holism is mistaken, although it is widely endorsed. The required token-token identifications underlying the various putative realizations cannot be had without accompanying inconsistencies. But even if there is little reason to think that social science properties such as being a team are multiply realizable, explanatory holism has nevertheless been vindicated. The key reason, of course, is that explanatory individualism presupposes the obtaining of token-token identities between social and individualistic objects. As a consequence of the failure of token-token identities to obtain, the relevant sortal predicates of the social sciences must be taken to apply to entities (if they exist) that are distinct from the entities of the individualistic sciences, and this entails that typetype identities between social and individualistic properties/relations must be rejected too: the predicates in question cannot even be taken to be coextensive- they do not apply to the same things, not even at times.

It is important to realize, however, that the fact that reductive token-token identities cannot be defended does not show that there really are such ontologically irreducible social objects. Whether the relevant sortal predicates actually have application, and whether the singular terms in question really refer, are further questions, and for all I have said they remain unanswered. (What I have argued is merely that if the sortal predicates in question have application, and if the corresponding names refer, then the sortal properties expressed must be taken to be exemplified by referents/objects that are irreducible.) There is insufficient space here to address the realism question, but it is worth noting that one important consideration is the Eleatic principle, which says that to be is to make a causal difference (see e.g. Armstrong 1997, pp. 41-43). If this principle is accepted, then, in order to defend the reality of ontologically irreducible social objects, one will have to show that such objects have causal abilities beyond those of the interrelated individuals - or the sums of (the temporal parts of) such individuals - that putatively compose (constitute) them. ${ }^{37}$

Lastly, it would be interesting investigating to what extent the reasoning of this paper generalizes to other special sciences, such as psychology, biology, chemistry etc. For example, to what extent do issues about extensionality arise in other fields? Can the states of affairs maneuver be plausibly invoked to handle potential issues about extensionality, so that reductive token-token identifications can be consistently carried through? (Notably, suspect deontic relations will not figure in such accounts.) Are properties in the relevant special science "flatly" multiply realized by properties picked out by some underlying primary science?

But I leave such investigations for future work.

Acknowledgements Many thanks to three anonymous reviewers for Synthese for their valuable feedback. Earlier versions of this paper were presented at Lund University, October 2013 and November 2014 (first as a department lecture, then at the Higher Seminar in Theoretical Philosophy); at the Social Complexes 2 conference in Gothenburg, June 2015; and at the inaugural meeting of the Nordic Network in Metaphysics in Uppsala, October 2015. Thanks to the audiences for helpful comments and constructive criticisms. Special

37 I discuss this issue in more detail elsewhere; see my (2014a, b). List and Spiekermann (2013) provide a recent and sophisticated defense of social level causation in terms of difference making. 
thanks to Jeroen Smid for helpful discussions. The writing of this paper was funded by the Swedish Research Council (Research Grant 421-2011-1694) and by Riksbankens Jubileumsfond (Research Grant P15-0744:1).

Open Access This article is distributed under the terms of the Creative Commons Attribution 4.0 International License (http://creativecommons.org/licenses/by/4.0/), which permits unrestricted use, distribution, and reproduction in any medium, provided you give appropriate credit to the original author(s) and the source, provide a link to the Creative Commons license, and indicate if changes were made.

\section{References}

Armstrong, D. M. (1989). Universals: An opinionated introduction. London: Westview press.

Armstrong, D. M. (1997). A world of states of affairs. Cambridge: Cambridge University Press.

Baker, L. R. (2007). The metaphysics of everyday life: An essay in practical realism. Cambridge: Cambridge University Press.

Baxter, D. L. M. (1988a). Many-one identity. Philosophical Papers, 17(3), 193-216.

Baxter, D. L. M. (1988b). Identity in the loose and popular sense. Mind, 97(388), 575-582.

Baxter, D. L. M. (2014). Identity, discernibility, and composition. In D. L. M. Baxter \& A. J. Cotnoir (Eds.), Composition as identity (pp. 244-253). Oxford: Oxford University Press.

Bhargava, R. (1992). Individualism in social science: Forms and limits of a methodology. Oxford: Oxford University Press.

Bickle, J. (2013). Multiple realizability. In E. N. Zalta (Ed.), Stanford encyclopedia of philosophy, http:// plato.stanford.edu/entries/multiple-realizability/.

Brown, W. J. (1905/2008). The personality of the corporation and the state (1905). Journal of Institutional, Economics, 4(2), 255-273.

Cameron, R. P. (2014). Parts generate the whole, but they are not identical to it. In D. L. M. Baxter \& A. J. Cotnoir (Eds.), Composition as identity (pp. 90-107). Oxford: Oxford University Press.

Casati, R., \& Varzi, A. (2014). Events. In E. N. Zalta (Ed.), Stanford encyclopedia of philosophy, http:// plato.stanford.edu/entries/events/.

Causey, R. L. (1972). Attribute-identities in microreductions. Journal of Philosophy, 69(14), 407-422.

Clapp, L. (2001). Disjunctive properties: Multiple realizations. Journal of Philosophy, 98(3), 111-136.

Cole, J. C. (2014). An abstract status function account of corporations. Philosophy of the Social Sciences, 44(1), 23-44.

Copp, D. (1984). What collectives are: Agency, individualism and legal theory. Dialogue, 23(2), 249-269.

Cotnoir, A. J. (2014). Composition as identity. In D. L. M. Baxter \& A. J. Cotnoir (Eds.), Composition as identity (pp. 3-23). Oxford: Oxford University Press.

Currie, G. (1984). Individualism and global supervenience. The British Journal for the Philosophy of Science, 35(4), 345-358.

Dizadji-Bahmani, F., Frigg, R., \& Hartmann, S. (2010). Who's afraid of nagelian reduction? Erkenntnis, 73(3), 393-412.

Elder-Vass, D. (2010). The causal power of social structures: Emergence, structure and agency. Cambridge: Cambridge University Press.

Elder-Vass, D. (2014). Redescription, reduction, and emergence: A response to Tobias Hansson Wahlberg. Philosophy of the Social Sciences, 44(6), 792-797.

Effingham, N. (2010). The metaphysics of groups. Philosophical Studies, 149(2), 251-267.

Epstein, B. (2009). Ontological individualism reconsidered. Synthese, 166(1), 187-213.

Epstein, B. (2015). The ant trap: Rebuilding the foundations of the social sciences. Oxford: Oxford University Press.

Fine, K. (1999). Things and their parts. Midwest Studies in Philosophy, 23(1), 61-74.

Fine, K. (2003). The non-identity of a material thing and its matter. Mind, 112(446), 195-234.

Fodor, J. (1974/1994). Special sciences (or: The disunity of science as a working hypothesis). In M. Martin \& L. C. McIntyre (Eds.), Readings in the philosophy of social science, 1994 (pp. 687-699). Cambridge, MA: The MIT Press.

Fodor, J. (1997). Special sciences: Still autonomous after all these years. Philosophical Perspectives, 11, $149-163$.

Frege, G. (1884/1980). The foundations of arithmetic (J. L. Austin Ed., English Trans., 2nd revised ed.). Northwestern university Press, Evanston. 
Gallois, A. (1998). Occasions of identity: The metaphysics of persistence, change, and sameness. Oxford: Oxford University Press.

Geach, P. T. (1980). Reference and generality (selections). In M. C. Rea (Ed.), Material constitution: A reader, 1997. Oxford: Rowman \& Littlefield Publishers.

Gerner, K. (Ed.). (2015). Vad hade hänt om:åtta kontrafaktiska historier. Lund: Historiska Media.

Giddens, A., Duneier, M., Appelbaum, R. P., \& Carr, D. (2014). Introduction to sociology (Seagull ed.). New York: W. W. Norton \& Company.

Gilbert, M. (1989). On social facts. Princeton: Princeton University Press.

Gillett, C. (2002). The dimensions of realization: A critique of the standard view. Analysis, 62(4), 316-323.

Gillett, C. (2003). The metaphysics of realization, multiple realizability, and the special sciences. Journal of Philosophy, 100(11), 591-603.

Goodman, N. (1966). The structure of appearance (2nd ed.). Indianapolis: Bobbs-Merrill Company.

Greve, J. (2012). Emergence in sociology: A critique of nonreductive individualism. Philosophy of the Social Sciences, 42(2), 188-223.

Hansson, T. (2007). The problem(s) of change revisited. Dialectica, 61(2), 265-274.

Hansson Wahlberg, T. (2009a). 4-D objects and disposition ascriptions. Philosophical Papers, 38(1), 35-72.

Hansson Wahlberg, T. (2009b). Objects in time-studies of persistence in B-time. Doctoral dissertation. Lund: Media-Tryck, www.fil.lu.se/en/department/staff/TobiasHanssonWahlberg/.

Hansson Wahlberg, T. (2010). The tenseless copula in temporal prediction. Erkenntnis, 72(2), 267-280.

Hansson Wahlberg, T. (2014a). Elder-Vass on the causal power of social structures. Philosophy of the Social Sciences, 44(6), 774-791.

Hansson Wahlberg, T. (2014b). Causally redundant social objects: Rejoinder to Elder-Vass. Philosophy of the Social Sciences, 44(6), 798-809.

Hansson Wahlberg, T. (2014c). Institutional objects, reductionism and theories of persistence. Dialectica, $68(4), 525-562$.

Hawthorne, J. (2003). Identity. In M. J. Loux \& D. W. Zimmerman (Eds.), The Oxford handbook of metaphysics. Oxford: Oxford University Press.

Heil, J. (2012). The universe as we find it. Oxford: Oxford University Press.

Hindriks, F. (2008). The status account of corporate agents. In B. Schmid, et al. (Eds.), Concepts of sharedness-New essays on collective intentionality (pp. 119-144). Frankfurt: Ontos Verlag.

Hovda, P. (2014). Logical considerations on composition as identity. In D. L. M. Baxter \& A. J. Cotnoir (Eds.), Composition as identity (pp. 192-210). Oxford: Oxford University Press.

Johnston, M. (1987). Is there a problem about persistence? Aristotelian Society Supplementary, 61, 107-135.

Kim, J. (1976/1993). Events as property exemplifications. In Supervenience and mind: Selected philosophical essays. Cambridge: Cambridge University Press.

Kim, J. (1992). Multiple realization and the metaphysics of reduction. Philosophy and Phenomenological Research, 52(1), 1-26.

Kim, J. (1999). Making sense of emergence. Philosophical Studies, 95(1-2), 3-36.

Kim, J. (2005). Physicalism, or something near enough. Princeton: Princeton University Press.

Kincaid, H. (1986/1994). Reduction, explanation, and individualism. In M. Martin \& L. C. McIntyre (Eds.), Readings in the philosophy of social science, 1994 (pp. 497-513). Cambridge, MA: The MIT Press.

Kincaid, H. (1990/1994). Defending laws in the social sciences. In M. Martin \& L. C. McIntyre (Eds.), Readings in the philosophy of social science, 1994 (pp. 111-130). Cambridge, MA: The MIT Press.

Kincaid, H. (2009). Causation in the social sciences. In H. Beebe, C. Hitchcock, \& P. Menzies (Eds.), The Oxford handbook of causation (pp. 726-743). Oxford: Oxford University Press.

Koslicki, K. (2008). The structure of objects. Oxford: Oxford University Press.

Kripke, S. L. (1980). Naming and necessity. Cambridge, MA: Harvard University Press.

Leonard, H. S., \& Goodman, N. (1940). The calculus of individuals and its uses. The Journal of Symbolic Logic, 5(2), 45-55.

Lewis, D. (1986). On the plurality of worlds. Oxford: Blackwell Publishing.

Lewis, D. (1991). Parts of classes. Oxford: Basil Blackwell.

Linnebo, Ö. (2012). Plural quantification. In E. N. Zalta (Ed.), Stanford encyclopedia of philosophy, https:// plato.stanford.edu/entries/plural-quant/.

List, C., \& Spiekermann, K. (2013). Methodological individualism and holism in political science: A reconciliation. American Political Science Review, 107(4), 629-643.

Little, D. (1991). Varieties of social explanation: Introduction to the philosophy of social science. Boulder: Westview Press. 
Little, D. (2016). New directions in the philosophy of social science. London: Rowman \& Littlefield.

Locke, J. (1689/1997). An essay concerning human understanding. London: Penguin Books.

Lowe, E. J. (1988). The problems of intrinsic change: Rejoinder to lewis. Analysis, 48(2), 72-77.

Lowe, E. J. (2009). More kinds of being: A further study of individuation, identity, and the logic of sortal terms. Oxford: Wiley-Blackwell.

Lukes, S. (1968/1994). Methodological individualism reconsidered. In M. Martin \& L. C. McIntyre (Eds.), Readings in the philosophy of social science, 1994 (pp. 451-458). Cambridge, MA: The MIT Press.

MacCormick, N., \& Weinberger, O. (1986). An institutional theory of law. Dordrecht: D. Reidel Publishing Company.

Martin, M., \& McIntyre, L. C. (Eds.). (1994). Readings in the philosophy of social science. Cambridge, MA: The MIT Press.

McLaughlin, B. P. (1992/2008). The rise and fall of British emergentism. In M. A. Bedau \& P. Humphreys (Eds.), Emergence: Contemporary readings in philosophy and science, 2008 (pp. 19-59) Cambridge, MA: The MIT Press.

McLaughlin, B., \& Bennett, K. (2011). Supervenience. In E. N. Zalta (Ed.), Stanford encyclopedia of philosophy, http://plato.stanford.edu/entries/supervenience/.

Mellor, D. H. (1995). The facts of causation. London: Routledge.

Merricks, T. (1999). Composition as identity, mereological essentialism, and counterpart theory. Australasian Journal of Philosophy, 77(2), 192-195.

Nagel, E. (1961/1979). The structure of science: Problems in the logic of scientific explanation. Indianapolis: Hackett Publishing Company.

Oppenheim, P., \& Putnam, H. (1958). Unity of science as a working hypothesis. In H. Feigl, M. Scriven, \& G. Maxwell (Eds.), Minnesota studies in the philosophy of science (Vol. II, pp. 3-36). Minneapolis: University of Minnesota Press.

Parkin, M., \& King, D. (1995). Economics (2nd ed.). Wokingham: Addison-Wesley.

Polger, T. W., \& Shapiro, L. A. (2008). Understanding the dimensions of realization. Journal of Philosophy, 105(4), 213-222.

Putnam, H. (1975). Mind, language and reality—philosophical papers (Vol. 2). Cambridge: Cambridge University Press.

Quinton, A. (1975-1976). Social objects. Proceedings of the Aristotelian Society, 76, 1+viii-27+viii.

Ritchie, K. (2013). What are groups? Philosophical Studies, 166(2), 257-272.

Ruben, D.-H. (1985). The metaphysics of the social world. London: Routledge \& Kegan Paul.

Russell, B. (1903). The principle of mathematics. Cambridge: At the University Press.

Russell, B. (1912/1980). The problems of philosophy. Oxford: Oxford University Press.

Rychter, P. (2009). There is no puzzle about change. Dialectica, 63(1), 7-22.

Sawyer, R. K. (2002). Nonreductive individualism: Part I-Supervenience and wild disjunction. Philosophy of the Social Sciences, 32(4), 537-559.

Sawyer, R. K. (2003). Nonreductive individualism: Part II-social causation. Philosophy of the Social Sciences, 33(2), 203-224.

Sawyer, R. K. (2005). Social emergence: Societies as complex systems. Cambridge: Cambridge University Press.

Sawyer, R. K. (2012). Response to "Emergence in Sociology". Philosophy of the Social Sciences, 42(2), $270-275$.

Schaffer, J. (2009). On what grounds what. In D. J. Chalmers, D. Manley, \& R. Wasserman (Eds.), Metametaphysics: New essays on the foundations of ontology (pp. 347-383). Oxford: Oxford University Press.

Schaffer, J. (2016). Social construction as grounding; Or: Fundamentality for feminists, a reply to Barnes and Mikkola. Philosophical Studies. doi:10.1007/s11098-016-0738-8.

Schaffner, K. F. (1967). Approaches to reduction. Philosophy of Science, 34(2), 137-147.

Schaffner, K. F. (2012). Ernest Nagel and reduction. Journal of Philosophy, 109(8-9), 534-565.

Schmitt, F. F. (Ed.). (2003). Socializing metaphysics: The nature of social reality. Lanham: Rowman \& Littlefield Publishers.

Searle, J. R. (1990/2002). Collective intentions and actions. In Consciousness and language, 2002 (pp. 90-105). Cambridge: Cambridge University Press.

Searle, J. R. (1992). The rediscovery of the mind. Cambridge, MA: The MIT Press.

Searle, J. R. (1995). The construction of social reality. London: Penguin Books.

Searle, J. R. (2010). Making the social world: The structure of human civilization. Oxford: Oxford University Press. 
Shapiro, L. A. (2000). Multiple realizations. Journal of Philosophy, 97(12), 635-654.

Sider, T. (2001). Four-dimensionalism: An ontology of persistence and time. Oxford: Oxford University Press.

Simons, P. (1987). Parts: A study in ontology. Oxford: Oxford University Press.

Sklar, L. (1967). Types of inter-theoretic reduction. British Journal for the Philosophy of Science, 18(2), $109-124$.

Smart, J. J. C. (1959). Sensations and brain processes. Philosophical Review, 68(April), 141-156.

Strawson, P. F. (1959). Individuals: An essay in descriptive metaphysics. London: Routledge.

Tuckman, B. W. (1965/2001). Developmental sequence in small groups. Group Facilitation: A Research and Applications Journal, 3, 66-81.

Tuomela, R. (1995). The importance of us: A philosophical study of basic social notions. Stanford: Stanford University Press.

Uzquiano, G. (2004). The supreme court justices: A metaphysical puzzle. Noûs, 38(1), 135-153.

van Inwagen, P. (1990). Four-dimensional objects. Noûs, 24(2), 245-255.

van Inwagen, P. (2006). Can mereological sums change their parts? The Journal of Philosophy, 103(12), $614-630$.

Watkins, J. W. N. (1957/1994). Historical explanations in the social sciences. In M. Martin \& L. C. McIntyre (Eds.), Readings in the philosophy of social science, 1994 (pp. 441-450). Cambridge, MA: The MIT Press.

Wiggins, D. (1968). On being in the same place at the same time. Philosophical Review, 77(1), 90-95.

Wiggins, D. (2001). Sameness and substance renewed. Cambridge: Cambridge University Press.

Williams, D. C. (1953). On the elements of being: I. Review of Metaphysics, 7(1), 3-18.

Winther, R. G. (2009). Schaffner's model of theory reduction: Critique and reconstruction. Philosophy of Science, 76(2), 119-142.

Zahle, J. (2003). The individualism-holism debate on intertheoretic reduction and the argument from multiple realization. Philosophy of the Social Sciences, 33(1), 77-99.

Zahle, J. (2016). Methodological holism in the social sciences. In E. N. Zalta (Ed.), Stanford encyclopedia of philosophy, http://plato.stanford.edu/entries/holism-social/.

Zahle, J., \& Collin, F. (Eds.). (2014). Rethinking the individualism-holism debate: Essays in the philosophy of social science. London: Springer. 